\title{
The Importance of Prison Farms: Evidence from Malawi’s Prisons
}

\author{
Dr Hastings B. Moloko ${ }^{1}$, Prof. Davis H. Ng'ong'ola ${ }^{2} \&$ Mr Henry Kamkwamba ${ }^{2}$ \\ ${ }^{1}$ University of Malawi, Malawi \\ ${ }^{2}$ Lilongwe University of Agriculture and Natural Resources, Malawi \\ Correspondence: Dr Hastings B. Moloko, University of Malawi, Malawi. Tel: 265-888-843-209. E-mail: \\ hmoloko@poly.ac.mw
}

Received: February 21, 2018 Accepted: March 9, 2018 Online Published: April 30, 2018

doi:10.5539/sar.v7n3p9 URL: https://doi.org/10.5539/sar.v7n3p9

\begin{abstract}
While Malawi's per capita cereal production may be higher than her per capita cereal consumption, Malawi is a net cereal importer and thus food insecure. The food situation is much worse in Malawi's prisons because inmates generally eat one meal per day.

The general objective of this study was to determine the importance of farms in Malawi's prisons by comparing food insecurity in prisons with farms to that in prisons without farms. Using structured questionnaires in face to face interviews, the study collected data from 1000 prisoners and 30 officers-in-charge from all prisons in the country. The data was analysed using Stata 12 and employed the probit and the Foster-Greer-Thorbecke (FGT) models as an analytical tools.

Results from the analysis showed that practically all prisoners in Malawi's prisons were food insecure. There was a higher perception of food insecurity in prisons without farms than there was in prisons with farms. Conditions of severe food insecurity were experienced more in non-farmed prisons than in farmed prisons, and more prisoners in non-farmed prisons depended on food brought to them from their homes. Food insecurity was more prevalent in prisons without farms than in prisons with farms.
\end{abstract}

Keywords: Malawi's prisons, occurrence of food insecurity, severity of food insecurity

\section{Introduction}

Politically, Malawi is divided into four regions, these being the Northern, the Central, the Eastern and the Southern regions. There are six prisons with a prisoner population of 1,717 in the Northern region. In the Central region, there are eight prisons with a prisoner population of 3,784. The Eastern region has eight prisons with 4,072 prisoners, while the Southern region has 3,025 prisoners in eight prisons. There were 12,598 prisoners in Malawi's 30 prisons in 2016 when this study was conducted.

Statement of the Problem: Although Malawi is generally food insecure, it is common in Malawi that most people consume three meals per day. What differs is mainly the quality, quantity and variety of the food that they eat. Inmates in Malawi's prisons, however, generally eat one meal per day (African Commission on Human and Peoples' Rights, 2002; Penal Reform International, 2005). These reports mention food issues as observations made in relation to health and human rights. None of these reports showed evidence of any studies having been conducted to analyse prisoners' access to food in prisons with farms compared to that in prisons without farms. This study identified this as a problem. The study, therefore, intended to make this comparison and fill this knowledge gap.

Justification of the Study: The overall objective of Malawi's Food and Nutrition Security Policy is to significantly improve the food and nutrition security of the Malawi population (Malawi Government, 2005). The specific objective of the Food Security Policy is to guarantee that all men, women and youth in Malawi have, at all times, physical and economic access to sufficient nutritious food required to lead a healthy and active life (Malawi Government, 2006). Since prisons accommodate about 0.08 percent of the Malawi population, it is important that prisons are food secure and that every prisoner has access to not less than the minimum meal requirement. Given the Malawi Government's commitment to ensuring food security, it was important that this study be carried out so that issues of prisoners' access to food are analysed and comparisons made between prisons with farms and prisons without farms. It was important to study and understand these parameters in order 
to lay the foundation upon which efforts to improve and re-engineer the food situation in Malawi's prisons could be based. This would enable policy makers and prison management to take appropriate policy and budgetary measures regarding prison subvention, strategic resource allocation, food production or procurement, and food demand and consumption levels to accurately address the problem and ensure prison food preparedness and improve prison food security. Also, since no study had been conducted in this area, it was important to conduct this study so that the existing knowledge gap could be filled.

Objectives of the Study: The general objective of this study was to demonstrate the importance of prison farms by analysing prisoners' access to food in prisons with farms compared to that in prisons without farms. The specific objectives of the study were:

i. To analyse the perception of food sufficiency in prisoners from prisons with farms compared to that in prisons without farms;

ii. To determine the number of meals per week that prisoners received from home in prisons with farms compared to that in prisons without farms, and

iii. To determine food security occurrences and frequencies in prisons with farms compared to that in prisons without farms.

Limitations of the Study: There were two major limitations to the study. The first was that all interviewees were male. This was because, for security reasons, the research team was only allowed to access prisoners that committed less serious offenses. Such prisoners were allowed to go out for farming activities because they were considered a lower security risk. The research team was advised to interview the sampled ones as they carried out their farming chores. The second limitation was that no female prisoners were in this category, not necessarily because they committed serious crimes, but because female prisoners were not allowed to go out for farming duties and the research team was not allowed to enter into the female side of the prison. As a result of these two limitations only 1000 male prisoners, instead of the required 1418 prisoners were interviewed.

The food situation in Malawi: The Millennium Development Goals (MDGs) through the medium term development strategy, the Malawi Growth and Development Strategy (MGDS), identified nine key priority development goals (Malawi Government, 2010). The first of these development goals was to eradicate extreme poverty and hunger. To achieve this, the Government's target was to halve, between 1990 and 2015, the proportion of people who suffered from hunger. One of the indicators for monitoring hunger was the proportion of the population living below the minimum level of dietary energy consumption of 2,100 kilocalories per person per day (Ecker \& Qaim, 2008; Malawi Government, 1999).

Malawi is an aggregate net exporter of food. The bulk of the food exports, however, are non-cereals such as tea and sugar and so although the country is a net food exporter, it remains a net importer of cereals and thus food insecure. Maize is the staple food in Malawi (De Graaff, 1985; Kidane, et al., 2006; World Bank, 2008; Food and Agriculture Organisation [FAO], 2010; International Food Policy Research Institute [IFPRI], 2012; FAO, 2015).

The food situation in Malawi's prisons: It is a requirement of the United Nations that every prisoner should be provided, by the administration at the usual hours, with food of nutritional value adequate for health and strength, of wholesome quality and well prepared and served (Medecins Sans Frontieres, 2009). The Malawi Prison Act Cap. 9:02, (1983) provides a dietary schedule for prisoners belonging to various categories of prisons. Despite these legally binding dietary guidelines, the practice on the ground is different. The African Commission on Human and Peoples' Rights ( 2002) observed that Malawian prisoners received only one meal per day and that meals were not balanced as prisoners ate the same food every day. The report also observed that the meals comprised of maize (nsima) and boiled beans and sometimes pigeon peas or vegetables. Neither meat nor fish was provided but salt was available in all prisons. This is a typical case of food insecurity.

\section{Materials and Methods}

Data Collection Techniques: Both primary and secondary data were collected using questionnaires, one administered to prisoners, and the other to prison officers-in-charge. A total of 1,000 male prisoners from all the 30 prisons were randomly selected and interviewed using questionnaires administered in face to face interviews. Secondary data were collected from official records obtained from the Malawi Prison Service Headquarters and the various prisons that were visited.

Data Analysis: Data were entered in Excel and analysed using Stata 12. The output from the analysis was reported using descriptive statistics such as means, proportions and percentages.

Sampling Methods: All prisons in Malawi formed the field of study and every inmate, except those that had been in prison for less than four weeks, was an eligible interviewee. The four-week requirement is a normal 
procedure followed by the USAID-funded Food and Nutrition Technical Assistance (FANTA) project which developed a questionnaire (Maxwel \& Frankenberger, 1992; Swindale \& Bilinsky, 2006) upon which the questionnaires used in this study were based. In order to select respondents from the population of inmates, the stratified random sampling and simple random sampling methods were used. The stratified random sampling method was applied to select $n$ units out of $N$ sub-populations called strata. In this case, each prison was a strata and from each strata $n$ number of inmates were selected using simple random sampling in order to give each prisoner an equal chance of being selected (Bryars, 1983; Agresti, 1996; Zikmund, 1997; McGill, McLennan \& Migliorini, 2000). In order to select participating inmates, tables of random numbers (Magnani, 1997) were used. In selecting prison officers for the interview, the purposive sampling method was used.

Sample Size: For more precision on sample size calculation, when population size and population proportions are known, the formula given below is used (Kothari, 2004).

$$
n=\frac{z^{2}}{e^{2}} \frac{p \cdot q \cdot N}{(N-1)+z^{2} \cdot p \cdot q}
$$

where $n=$ sample size, $z=1.96=$ z-value yielding $95 \%$ confidence level, $p=$ proportion of the population of interest, $q=1-p, N=12,598=$ the population of interest, $e=5 \%=$ absolute error in estimating $p$.

The population proportion for each prison was calculated as in Equation (2).

$$
\text { Prison proportion, } p=\frac{\text { Number of prisoners at a given prison }}{\text { Total prisoner population in Malawi }}
$$

In 2016, the total number of, both convicted and un-convicted, inmates in Malawi's prisons was 12,598 (Malawi Government, 2016), while the population of Malawi as given by the United Nations Development Program (UNDP) in its 2011 Human Development Report was 15,380,900 (UNDP, 2011). Following the reasoning articulated above and applying Equation (1), the value of $n$, the sample size, was found to be 1418 . However, only 1,000 inmates were interviewed because of the study limitations.

Data were collected by three trained interviewers using a questionnaire that had been reviewed by a group of key informants, refined by eight prisoners that were representative of the survey population but who were not part of the survey sample, and pretested on fifteen prisoners through a preliminary survey. Data collected were subjected to regression and correlation analysis and results summarized.

\section{Model Specification}

Data from the prisoner questionnaire were entered in SPSS and then imported into STATA 11 for analysis using the probit model in order to analyse prisoners' perceptions of food sufficiency and determine the number of meals received from home. The Foster Greer Thorbeck model was used to determine prisoners' food security occurrences and frequencies.

\section{The Probit Model}

Data from the questionnaire that was administered on inmates were analysed using the probit model in order to establish relationships between and among variables. The probit model was considered appropriate because the questionnaire resulted in dichotomous variables which could easily be analysed using this model. The prisons were categorized in terms of whether a prison had a farm or not. A prison was considered to have a farm if it owned more than six hactares of farm land and otherwise, if it had less than that.

Following the arguments presented by (Maddala, 1992; Wooldridge, 2002; Verbeck, 2004; Gujarati D. , 2004; Greene, 2003), a regression model shown in Equation (3) was assumed.

$$
y_{i}^{*}=\beta_{0}+\sum_{j=1}^{k} \beta_{j} X_{i j}+U_{i}
$$

where $y_{i}^{*}$ is not observed, in which case it is a "latent" variable, then what is observed is a dummy variable $y$, defined by Equation (4).

$$
y_{i}=1 \text { if } y^{*}>0
$$

$y_{i}=0$ otherwise

This was the basis of both the probit model. In equation (3) it is assumed that a latent variable exists for which a dichotomous realization is observed. For example, if the observed dummy variable is whether or not the prisoner 
is food secure, $y_{i}^{*}$ would be defined as "prisoner's perception of being food secure".

From equation (4), multiplying $y_{i}^{*}$ by any positive constant doe not change $y_{i}$. So, if $y_{i}$ was observed, the $\beta^{\prime}$ s in (3) could be estimated only up to a positive multiple. As a result, it is customary to assume $\operatorname{var}\left(U_{i}\right)=1$. This fixes the scale of $y_{i}^{*}$. From equations (3) and (4), Equation (5) was obtained.

$$
P_{i}=\operatorname{Prob}\left(y_{i}=1\right)=\operatorname{Prob}\left[U_{i}>-\left(\beta_{0}+\sum_{j=1}^{k} \beta_{j} X_{i j}\right)\right]=1-\mathrm{F}\left[-\left(\beta_{0}+\sum_{j=1}^{k} \beta_{j} X_{i j}\right)\right]
$$

where $\mathrm{F}$ is the cumulative distribution function of $U$. Since the distribution of $U$ is symmetric, given that $1-$ $\mathrm{F}(-\mathrm{Z})=\mathrm{F}(\mathrm{Z})$, then

$$
P_{i}=\mathrm{F}\left(\beta_{0}+\sum_{j=1}^{k} \beta_{j} X_{i j}\right)
$$

Because the observed $y_{i}$ were realizations of a binomial process with probabilities given by (5), the likelihood function became

$$
\mathrm{L}=\prod_{v i=1} P_{i} \prod_{v i=0}\left(1-P_{i}\right)
$$

In (6), the functional form for $\mathrm{F}$ depended on the assumption made for the error term $U$. If the cumulative distribution of $U_{i}$ was logistic, a logit model would be obtained. If the errors in $U_{i}$ in (3) followed normal distribution, a probit model would be gotten. In that case Equation (8) would be gotten.

$$
\mathrm{F}\left(Z_{t}\right)=\int_{-\infty}^{\frac{Z_{t}}{\sigma}} \frac{1}{\sqrt{2 \pi}} \exp \left(-\frac{t^{2}}{2}\right) d t
$$

The cumulative normal and logistic distributions are generally very close to each other, except at the tails, in that the logistic tail is slightly fatter than the probit tail as the normal curve approaches the axes more quickly than the logistic curve.

After estimating the parameters, $\beta_{i}$, it was important to predict the effects of changes in any of the independent variables on the probabilities of any observation of the dependent variable. These effects were called marginal effects, given by $\frac{d y}{d x}$, in the probit analyses given in this study. Marginal effects were calculated at different levels of the independent variables to get an idea of the range of variation of the resulting changes in probabilities (Maddala, 1992; Gujarati, 2004).

The probit model has been used widely in analysing data in various research endeavours. For example, the probit model was used to analyse factors impacting adoption of genetically modified cotton (Banerjee \& Martin, 2009). The model was also used to analyse the effects of some socio-demographic factors on the decision of the consumer to purchase packed or unpacked fluid milk in Sivas, Turkey. In that study, four estimators (household size, income, milk preferences reason, and milk price) were found statistically significant (Uzunoz \& Akcay, 2012). The probit models were also been used in management research as analytical tools to the extent that they appeared in 15\% of all articles published in the Strategic Management Journal in 2005 (Hoetker, 2007).

Each of the food security conditions of "anxiety", "insufficient quality", "un-preferred food", "limited variety", "unwanted food", "smaller meal", "fewer meals", "no-food-at-all", "sleeping hungry", "whole day and night", "augmenting", and "shameful means" was regressed against the independent variables of "age", "education", "how far", "meals per week", and "status". Table 1 carries descriptions of the variables. 
Table 1. Description of variables for the probit models

\begin{tabular}{ll}
\hline Dependent Variable & Variable Description \\
\hline Anxiety & Anxiety And Worry That There Would Not Be Enough Food In Prison \\
Insufficientquality & Insufficient Food Quality \\
Unpreferredfood & Not Eating The Kinds Of Food That One Preferred Because Of Lack Of Food \\
Limitedvariety & Eating A Limited Variety Of Foods Due To Lack Of Food \\
Unwantedfood & Eating Unwanted Food Because There Was No Other Food To Eat \\
Smallermeal & Eating A Smaller Meal Than One Needed \\
Fewermeals & Eating Fewer Meals In A Day \\
Nofoodatall & Having No Food At All To Eat Because Food Was Not Available \\
Sleepinghungry & Going To Sleep At Night Hungry Because Food Was Not Available \\
Wholeday\&night & Going A Whole Day And Night Without Eating \\
Augmenting & Augmenting Food Intake Through Outside Supply \\
Shamefulmeans & Acquiring Food Through Borrowing, Begging Or Stealing \\
Independent Variables & Variable Description \\
Age & Age Of Prisoner In Years \\
Education & Education Level Of Prisoner In Years \\
Howfar & How far the prisoner's home or relatives are from prison \\
Meals $/$ week & Number Of Times Per Week Prisoner Received Meals From Home \\
Status & Social Status Of Prisoner, Eg, Rich/Important/Influential Or Poor \\
Prison & Prison Where Prisoner Is Incarcerated \\
\hline
\end{tabular}

\section{The Foster-Greer-Thorbecke (FGT) model}

The Foster-Greer-Thorbecke model was used to determine food security occurrences and frequencies in prisons with farms compared to those in prisons without farms. The FGT model is expressed as in Equation (8) (Gujarati, 2004).

$$
\mathrm{F}(\alpha)=\frac{1}{\mathrm{n}} \sum_{\mathrm{i}=1}^{\mathrm{q}}\left[\frac{\left(\mathrm{m}-\mathrm{y}_{\mathrm{i}}\right)}{\mathrm{m}}\right]^{\alpha}
$$

where $n$ is the number of sample prisoners; $\mathrm{y}_{\mathrm{i}}$ is the food caloric intake per adult equivalent of the $i^{\text {th }}$ prisoner; $\mathrm{m}$ is the cut-off between food security and insecurity (expressed in caloric requirements); $\mathrm{q}$ is the number of food-insecure prisoners; and $\alpha$ is the weight attached to the severity of food insecurity.

It must be noted, however, that $\mathrm{m}-\mathrm{y}_{\mathrm{i}}=0$ if $\mathrm{y}_{\mathrm{i}}>\mathrm{m}$. As for the weight $\alpha$, giving no weight to the severity of food insecurity is equivalent to assuming that $\alpha=0$. If that were done, the formula would collapse to $\mathrm{F}(0)=\frac{q}{n}$, which is called the head count ratio. The head count ratio or the incidence of food insecurity would be the share of the prison population whose food intake was below the food security threshold of 2,100 kilocalories. It was also possible for one using several food insecurity thresholds, say one for food insecure and another for extreme food insecure, to estimate the incidence of both food insecurity and extreme food insecurity. A weakness of the headcount ratio, however, is that it ignores the depth of food insecurity in that should the hungry become hungrier, the head count ratio would not change (United Nations, 2015).

Giving equal weight to the severity of food insecurity among all food insecure prisoners was equivalent to assuming that $\alpha=1$. If the sum of the numerator were taken, one would get the food insecurity gap, which when divided by $\mathrm{m}$ would give the food insecurity gap index (Gujarati, 2004). The food insecurity gap index would provide a better indication of the depth of food insecurity. It would also allow food insecurity comparisons and would provide an overall assessment of Malawi prisons' progress in curbing food insecurity. The food insecurity gap index would also help in the evaluation of Malawi's prison policies related to food and other initiatives. By multiplying the prisons' food insecurity gap index by both the food security threshold and the total number of prisoners in the country one would get the total amount of food needed to bring the food insecure prisoners out of food insecurity and up to the food security threshold (Gujarati, 2004). This means that the food insecurity gap index is an important measure beyond the head count ratio. If there were two prisons having similar headcount ratios, but different food insecurity gap indexes, it would mean that the prison with a higher food insecurity gap index had more severe food insecurity. The food insecurity gap index is additive, meaning that the index can be used as an aggregate food insecurity measure, as well as decomposed for various 
sub-groups of the prisoners (Sen, 1976).

The index $F(1)$ provided the possibility to estimate resources required to eliminate food insecurity. Giving weight to the severity of food insecurity among the most food insecure prisoners was equivalent to assuming that $\alpha>1$. Therefore, allowing $\alpha=2$, gave rise to Equation (10).

$$
\mathrm{F}(2)=\frac{1}{\mathrm{n}} \sum_{\mathrm{i}=1}^{\mathrm{q}}\left[\frac{\left(\mathrm{m}-\mathrm{y}_{\mathrm{i}}\right)}{\mathrm{m}}\right]^{2}
$$

This yielded the severity of food insecurity. The severity of food insecurity took into account not only the distance separating the food insecure from the food security threshold but also the inequality among the food insecure. That is, a higher weight was placed on those who were further away from the food security threshold (Foster, Greer, \& Thorbecke, 1984).

So, $F(0)$ was the percentage of food insecure prisoners, $F(1)$ the food insecurity gap and $F(2)$ the severity of food insecurity.

\section{Results and Discussion}

The specific objectives of this study were to analyse the perception of food sufficiency, to determine the number of meals per week that prisoners received from home, and to determine food security occurrences and frequencies in prisons with farms compared to those in prisons without farms. The results have, therefore, been presented and discussed following this same sequence.

Prisoners' perception of food sufficiency. The general perception of prisoners in all prisons in Malawi was that there was insufficient food in prison. However, 59 per cent of the prisoners in prisons with farms perceived themselves as being food sufficient compared to 49 per cent in prisons without farms. Conversely, 41 per cent of prisoners in farmed prisons indicated food insufficiency compared to 51 per cent in prisons without farms. This result suggested that one was better off food-wise when incarcerated in a prison with a farm and worse off in a prison without a farm. Table 2 shows the prisoners' perception of food sufficiency in prisons with farms compared to those in prisons without farms.

Table 2. Prisoners' perceptions on whether food received was sufficient

\begin{tabular}{lll}
\hline & Prison with farm & Prison without farm \\
\hline Sufficient & 59.3 & 48.7 \\
Insufficient & 40.97 & 51.3 \\
total & 100 & 100 \\
\hline
\end{tabular}

Table 3 contains results of the marginal effects from the robust regression of the probit models that were run to determine factors that affected the perception of conditions of food insufficiency in prisons with farms compared to those in prisons without farms.

Table 3. Factors affecting the perception of conditions of food insufficiency in prisons with and without farms.

\begin{tabular}{|c|c|c|c|c|c|c|c|c|c|c|}
\hline \multirow[t]{3}{*}{ Dependent Variable } & \multicolumn{10}{|c|}{ Independent Variables } \\
\hline & \multicolumn{5}{|c|}{ Prison with Farm, i.e. $>=6 \mathrm{Ha}$} & \multicolumn{5}{|c|}{ Prison without Farm, i.e. $<6 \mathrm{Ha}$} \\
\hline & Ageprisoner & Educationprisoner & Howfar & Meals & Status & Ageprisoner & Educationprisoner & Howfar & Meals & Status \\
\hline Anxiety & 0.000106 & 0.001118 & -0.024224 & $-0.085660^{* * * *}$ & $0.095198 * *$ & $0.008184 * * *$ & 0.001402 & $0.111606^{* *}$ & -0.021878 & $-0.095180^{* *}$ \\
\hline Unpreferredfood & 0.000268 & 0.006517 & -0.023282 & $-0.042319 * * *$ & -0.037752 & 0.002962 & 0.000672 & -0.029234 & $-0.035903^{*}$ & -0.042823 \\
\hline Limitedvariety & 0.000136 & 0.008528 & 0.011761 & $-0.050089^{* * * *}$ & $-0.070930^{* * *}$ & $0.006562^{* * * * *}$ & $0.016408^{* * * *}$ & 0.002299 & -0.012399 & $-0.092090^{* * *}$ \\
\hline Unwantedfood & 0.002921 & 0.008387 & -0.063043 & -0.026828 & $-0.079061 *$ & 0.003977 & 0.002663 & -0.043016 & 0.013332 & -0.032477 \\
\hline Smallmeal & 0.000162 & 0.009116 & -0.021597 & $-0.069223^{* * * *}$ & -0.019060 & $0.004389^{*}$ & -0.000190 & 0.031080 & $-0.044540^{*}$ & -0.056314 \\
\hline Fewermeals & 0.003100 & 0.006151 & -0.054762 & -0.024346 & -0.045153 & 0.000915 & 0.001589 & -0.020961 & -0.024805 & $-0.146802^{* * * *}$ \\
\hline Nofood & -0.000909 & 0.000798 & -0.025666 & -0.021713 & -0.030859 & 0.000374 & $-0.008514^{* * *}$ & -0.026790 & 0.010779 & $-0.054495^{*}$ \\
\hline Sleephungry & -0.000067 & $-0.012858^{* *}$ & -0.060623 & -0.023975 & -0.022482 & $0.004374 * *$ & -0.006483 & 0.000906 & 0.006296 & -0.047823 \\
\hline Day\&night & 0.000753 & $-0.008900^{* *}$ & -0.021120 & $-0.057568^{*}$ & -0.016844 & 0.002331 & $-0.006928^{*}$ & $-0.094432^{* * *}$ & 0.008649 & -0.003885 \\
\hline Augment & -0.001065 & $0.012451^{*}$ & 0.026967 & $0.058373 * *$ & 0.030610 & 0.001968 & -0.007854 & 0.087379 & $0.095732^{* * * *}$ & $0.168364 * * *$ \\
\hline Shamefulmeans & -0.001244 & 0.003567 & $0.087475^{* *}$ & $-0.039198^{*}$ & $0.084230^{*}$ & 0.000410 & -0.006891 & $0.228903^{* * * * *}$ & 0.028702 & 0.015008 \\
\hline
\end{tabular}

Note: Marginal effects reported

\footnotetext{
*** significant at $1 \%$, i.e. $p<0.01$

** significant at $5 \%$, i.e. $p<0.05$

* significant at $10 \%$, i.e. $p<0.10$
} 
Anxiety over food. In prisons with farms, the prisoner's age was an insignificant factor in determining the level of anxiety and worry over food, where as in prisons without farms, the prisoner's age significantly caused an increase in anxiety over food. This suggested that food was scarcer in prisons without farms and older prisoners had more difficulties to access it. The further away from prison that the prisoner's home was, caused an insignificant two per cent in the prisoner's anxiety over food at a farmed prisons, but caused a significant increase of 11 per cent if the prisoner was at a prison without a farm. Frequent receipt of home meals significantly reduced anxiety over food by about nine per cent at farmed prisons, while insignificantly reducing anxiety at non-farmed prisons. Being of higher status significantly increased the prisoner's anxiety over prison food by 10 per cent in farmed prisons and significantly reduced this perception by 10 per cent in non-farmed prisons. This was possibly because being of higher status meant that the prisoner was used to good life and having abundant good food and would thus find the prison food situation worrying. On the other hand, a prisoner of higher status would easily have access to alternative means of acquiring food and hence be less worried over prison food when everyone else was worried. Also prisoners of high status had the means to be able to bribe cooks and get bigger portions of food than other prisoners. This would also make them less anxious about food. It was, however, clear from the results that prisoners that were incarcerated at prisons with farms worried less about food than those at prisons without farms.

Eating un-preferred food. The number of meals per week that the prisoner received from home was the only significant factor that caused one to eat or not eat un-preferred food in prisons both with and without farms. An increase in the frequency of home-meal receipts, on the whole, caused a negative four per cent on prisoner's perception of eating un-preferred food, irrespective of whether their prison had or did not have a farm. Notes written down during interviews indicated that prisoners who often received meals from home did not rely on prison food. Those who received home meals every day did not eat much prison food. Because of this comfort, these prisoners ate more of the food that they preferred and perceived prison food as un-preferred.

Eating a limited variety. Both meals and status were of negative significance in affecting eating a limited variety of foods in prisons with farms. Frequently receiving meals from home caused a negative five per cent, while status caused a negative seven per cent in the prisoners' perception of eating a limited variety of foods. These results were not surprising because as the frequency of home meals and the level of status increased, one became better nourished, and better supplied even in variety of food and therefore found prison food less adequate in its variety.

In prisons without farms, prisoner age, education and status were significant factors in influencing one's perception of prison food being of limited variety. Prisoner age and education each had a positive influence of about one and two per cent respectively. Status caused a negative influence of about nine per cent. Prisoner age had a positive effect possibly because the older prisoners more readily understood food varieties and indeed found prison food to be of limited variety. Prisoner education also exerted a positive effect. This was also because education helped one to understand the six food groups and thus allowing him to find prison food to be of limited variety. But both prisoner age and education were insignificant factors in causing this perception in farmed prison. This is a possible indicator that access to food was comparably better in farmed prisons. Higher status, on the other hand, enabled the prisoner to negatively judge prison food variety, possibly because he had exposure to more and better food variety.

Eating unwanted food. Prisoner status significantly influenced the prisoners' perception of eating unwanted food in prisons with farms. Higher prisoner status caused a negative eight per cent in the prisoner's perception of prison food being unwanted. Again, the higher status would have exposed the prisoner to more appetising food from home thereby making him see prison food as unwanted. In prisons without farms, no variable was found to significantly influence prisoners' perception of eating unwanted food. This finding may mean that prisoners in prisons without farms were so desperate for food that they could not judge any food, not even prison food, as unwanted.

Eating a smaller meal. The number of meals per week received from home caused the prisoner to significantly perceive the prison ration as being small in prisons with farms. Receiving more meals from home caused a negative seven per cent in the prisoner's perception of the size of the prison ration being small. This could be attributed to the fact that home portions could be more generous thereby having the effect of making the prisoner see the prison ration as being smaller by comparison.

The age of the prisoner was of positive significance while the number of meals received from home was of negative significance in prisons without farms. The rationale given in earlier sections about the effect of home meals was applicable here also. However, the fact that older prisoners were more aware of the smallness of the 
meal size in non-farmed prisons was cause for concern. This could be an indication that food was scarce in non-farmed prisons and older prisoners became easy victims, possibly due to lack of physical strength to compete with the younger ones.

Eating fewer meals. No variable significantly influenced the perception of eating fewer meals in prisons with farms. This meant that prisoners in prisons with farms did not really feel that they ate fewer meals. This could be a pointer to the fact that farmed prisons were better endowed with food. Prisoner status, however, significantly caused a negative 15 per cent on the perception of eating fewer meals in prisons without farms. The negativity would arise from the fact that higher status would mean access to more meals from outside prison, thus, by comparison, making the prisoner aware that the prison provisions were fewer.

No food at all. In prisons with farms, no variable significantly caused the perception that there was no food at all to eat at the prison. This meant that in farmed prisons, they always had something to eat, possibly confirming the proposition that farmed prisons were better supplied with food. However, in prisons without farms, prisoner education and status negatively but significantly caused in the prisoner the perception that there was no food to eat at the prison. Prisoner education influenced this perception by nearly one per cent while status influenced it by five per cent. As was seen before, this was not surprising as an increase in both education and status would have exposed the prisoner to better opportunities which would enable him to spot shortfalls in prison rations. In spite of the aforesaid, this increased perception of there being no food at all to eat could be an indication that prisons without farms were finding it difficult to feed their prisoners.

Sleeping hungry. Prisoner education was a significant factor in causing the perception that the prisoner was sleeping hungry in prisons with farms. An increase in education caused a negative one per cent in this perception. Again, this was expected for reasons articulated earlier in this paper. In prisons without farms, prisoner age caused a small but positively significant influence in the perception that the prisoner was sleeping hungry. It was possible that the older prisoner slept hungry because in times when food was extremely scarce, the older prisoner lacked the physical strength to compete with the younger prisoners for food and so the older one slept hungry. On the other hand, this finding confirmed the earlier finding that prisons without farms had difficulties in feeding their inmates; the older prisoners simply being easier victims.

Day and night. Prisoner education and meals received from home were negative but significant factors in causing the perception of staying the whole day and night without eating. Being more educated caused a negative one per cent while receipt of more home-meals caused a negative six per cent in this perception in prisoners at prisons with farms. This was because higher education possibly allowed the prisoner to have alternative means of accessing food and receipt of more home-meals helped the prisoner not to stay a whole day and night without food.

In prisons without farms, education and how far from home the prisoner was, caused a negative but significant effect of about one per cent and nine per cent, respectively, on the prisoners' perception of staying a whole day and night without eating. It was expected that education would lower the perception of staying a whole day and night without food because of the capacity of the educated prisoner to find alternative sources of food. The anomaly was when prisoners who came from distant places showed a reduced perception of staying a whole day and night without food, and at a farm-less prison for that matter. The only plausible explanation for this scenario could be that these prisoners had completely lost hope or any sense of self-worth that they had resorted to simply accept life and situations as they unfolded. Possibly these prisoners had stayed a whole day and night without eating many times before so much so that it did not matter anymore now and they had accepted this as normal practice, hence their reduced perception of staying a whole day and night without eating. This finding was a possible indicator of severe food scarcity in prisons without farms.

Augmenting food intake. Prisoner education and receipt of home-meals were positively significant in augmenting food intake in farmed prisons. In non-farmed prisons, significant factors were meals and status. Receipt of more home meals caused a ten per cent increase in augmentation whereas higher status caused a 17 per cent increase. These results were expected as education, receipt of home meals, and status were factors that have been found to enable prisoners gain easy access to outside resources, including food. The fact that there was more augmentation with outside food in prisons without farms also meant that in these prisons food was scarcer.

Shameful Means. In farmed prisons, how far the prisoner's home was from prison, meals received from home, and the prisoner's status were significant factors in influencing the perception of obtaining food through shameful means such as borrowing, begging or stealing from other inmates or people. An increase in the distance between prison and the prisoner's home increased this perception by about nine per cent. This meant that increased distance to the prisoner's home, probably out of desperation, made the prisoner resort to these 
shameful means more and more. On the other hand, increased receipt of home-meals caused a four per cent reduction in this perception. This was expected as receipt of home meals would make a prisoner better fed and, therefore, have no need to beg, borrow or steal food from other people.

An increase in the prisoner's status, however, increased this perception by about eight per cent. This is another anomaly because, so far, it has been seen that prisoners of higher status lacked no food and, therefore, should have no reason to borrow, beg or steal food from anyone. The question that was asked to the inmates was "In the past four weeks, did you or any inmate at your prison resort to other means of acquiring food such as borrowing, begging or stealing from other inmates or people because there was not enough food?" If attention is focussed on "or any inmate", it may be seen that the prisoner could give a "yes" response not with respect to himself, but other inmates. If that respondent was one of higher status, chances were that he was the one from whom food was borrowed, begged or stolen, considering that he was the one in possession of more food than anyone else. Given the foregoing, the prisoner of higher status would likely know some inmates at his prison who resorted to shameful means of obtaining food, such as borrowing, begging or stealing. His "yes" must, therefore, be understood in the sense that an increase in the prisoner's status increased his perception of suffering from these shameful means.

In farm-less prisons, how far away the prisoner's home was from prison, significantly increased the prisoner's perception of engaging in shameful means of obtaining food. An increase in distance between prison and home increased this perception by about 23 per cent, meaning that prisoners from far away were more likely going to engage in this behaviour, possibly out of desperation. By comparison, increased distance caused a nine per cent increase in the perception of using shameful means in farmed prisons but caused an increase of 23 per cent in non-farmed prisons. This big percentage difference was a serious indicator of food scarcity in non-farmed prisons.

Meals per week received from home. Most prisoners did not receive meals from outside prison, and less than one percent received such meals every day of the week, irrespective of whether or not the prison had a farm. This was not surprising as most prisoners came from far from prison, making it difficult for relatives to visit often. Comparing farmed and non-farmed prisons, it transpired that 86 per cent of the prisoners from farmed prisons received no meals at all from home while 77 per cent of the prisoners from non-farmed prisons did not receive home meals. This meant that only 14 per cent of prisoners from farmed prisons received food from home when 23 per cent of prisoners from no-farmed prisons received food from home. This result gives evidence to the fact that prisoners in Malawi were better fed when imprisoned at a farmed prison than when at a non-farmed prison. Also, less than half a per cent of prisoners from prisons with farms received home meals every day of the week, when one per cent of those from prisons without farms received home meals every day. This is an indication of how desperate the food situation was in prisons without farms. Table 4 shows the number of meals per week that a prisoner received from home.

Table 4. Meals per Week Received from Home

\begin{tabular}{|c|c|c|c|c|c|c|c|c|}
\hline \multicolumn{9}{|c|}{ Meals per week $(\%)(n=1000)$} \\
\hline No. of meals/week & 0 & 1 & 2 & 3 & 4 & 5 & 7 & Total \\
\hline Without farm & 76.72 & 13.41 & 5.59 & 2.98 & 0.37 & 0 & 0.93 & 100 \\
\hline With farm & 85.53 & 7.78 & 4.32 & 1.08 & 0.43 & 0.43 & 0.43 & 100 \\
\hline Pearson Chi-square & 17.99 & $* * *$ & & & & & & \\
\hline
\end{tabular}

Prisoner food security occurrences and frequencies. Out of the eleven conditions of food insecurity which were studied, six were indications of less serious food insecurity while the other five were indications of severe food insecurity. The six indicators of less serious food insecurity were: anxiety, un-preferred food, limited variety, unwanted food, small meals and fewer meals. The five indicators of severe food insecurity were: no food at all, sleeping hungry, not eating whole day and night, augmenting and using shameful means. The results in Table 4 show that fewer prisoners in farmed prisons experienced the conditions of severe food insecurity compared to those in non-farmed prisons. For example, only eight per cent of the prisoners in farmed prisons experienced staying with no food at all versus 11 per cent in non-farmed prisons. In farmed prisons, 17 per cent slept hungry compared to 24 per cent in non-farmed prisons. Only ten per cent in farmed prisons stayed a whole day and night without eating versus 14 per cent in non-farmed prisons. In farmed prisons, 39 per cent augmented prison food with outside food compared to 45 per cent in non-farmed prisons. About 58 per cent in farmed prisons used shameful means of obtaining food compared to 65 per cent in non-farmed prisons. These results, therefore, showed that a prisoner was better off, food-wise, if incarcerated in a farmed prison than in a non-farmed prison. 
Table 5 presents prisoner food security occurrences and frequencies.

Table 5. Prisoner food security occurrences and frequencies

\begin{tabular}{lll}
\hline condition of food insecurity & Without farm & With farm \\
\hline Anxious & 60.52 & 62.2 \\
Unpreferred food & 80.82 & 83.8 \\
Limited variety & 82.12 & 79.48 \\
Unwanted food & 52.14 & 55.94 \\
Small meal & 76.54 & 75.59 \\
Fewer meals & 77.09 & 78.62 \\
No food & 11.36 & 7.78 \\
Sleep hungry & 24.39 & 17.06 \\
Whole day \& night & 13.59 & 9.5 \\
Augmenting & 45.44 & 38.88 \\
Shameful means & 64.8 & 58.32 \\
\hline
\end{tabular}

Food security prevalence. Prisoners in Malawi's prisons were found to be severely food insecure. The worst case scenario was prisoners in non-farmed prisons, where 95 per cent of the prisoners were severely food insecure compared to 79 per cent in farmed prisons. On the other hand, the most food secure prisoners (11 per cent) were those incarcerated in prisons with farms because only one per cent of those in non-farmed prisons considered themselves food secure. Table 6 shows prisoner food security prevalence in percentage terms.

Table 6. Food security prevalence

\begin{tabular}{lll}
\hline food security Status & With farm & Without farm \\
\hline Food secure & 11.3 & 1.3 \\
Mildly food insecure & 2.1 & 0.5 \\
Moderately food insecure & 7.3 & 3.4 \\
Severely food insecure & 79.3 & 94.8 \\
\hline
\end{tabular}

Note: Some columns do not add up to $100 \%$ due to rounding off errors.

\section{Conclusion}

About 41 per cent of the prisoners in prisons with farms indicated food insufficiency compared to 51 per cent in prisons without farms. The prisoner's age significantly caused an increase in anxiety over food and also caused a small but positively significant influence in the perception that the prisoner was sleeping hungry in prisons without farms. The prisoner's age and education were also significant factors in influencing one's perception of prison food being of limited variety but both were insignificant in prisons with farms. The prisoner's education and status negatively but significantly caused the perception that there was no food to eat at the prison. Older prisoners were more aware of the smallness of the meal size in non-farmed prisons. These findings were possible indications that food was scarce in non-farmed prisons.

The further away from prison that the prisoner's home was, caused an insignificant two per cent in the prisoner's anxiety over food in farmed prisons, but caused a significant increase of 11 per cent if the prisoner was at a prison without a farm. By comparison, increased distance caused a nine per cent increase in the perception of using shameful means in farmed prisons but caused an increase of 23 per cent in non-farmed prisons. Prisoners who came from distant places also showed a reduced perception of staying a whole day and night without food at a farm-less prisons, possibly indicating that these prisoners had completely lost hope or any sense of self-worth that they had resorted to simply accept life and situations as they unfolded. Prisoners incarcerated in prisons without farms whose homes were far away from prison were also so desperate for food that they could not judge any food, not even prison food, as being unwanted.

In prisons with farms, no variable significantly caused the perception that there was no food at all to eat at the prison. This meant that in farmed prisons, they always had something to eat, possibly confirming the proposition that farmed prisons were better supplied with food.

The fact that there was more augmentation with outside food in prisons without farms also meant that in these prisons food was scarcer. About 14 per cent of prisoners from farmed prisons received food from home 
compared to 23 per cent in non-farmed prisons. Fewer prisoners in farmed prisons experienced the conditions of severe food insecurity compared to those in non-farmed prisons. In non-farmed prisons, 95 per cent of the prisoners were severely food insecure compared to 79 per cent in farmed prisons. On the other hand, the most food secure prisoners (11 per cent) were those incarcerated in prisons with farms as only one per cent of those in non-farmed prisons considered themselves food secure. The findings in this paper gave evidence to the fact that prisoners in Malawi were more food secure and better fed when imprisoned at a prison with a farm than at a prison without a farm.

\section{References}

African Commission on Human and Peoples' Rights. (2002). Prisons in Malawi-Report on a Visit 17 to 28 June 2001 by Dr. V.M. Chirwa Special Rapporteur on Prisons and Conditions of Detention in Africa. Paris, France.

Agresti, A. (1996). An introduction to categorical data analysis. New York: Wiley and Sons Inc.

Banerjee S, Martin S. (2009). A Binary Logit - Analysis of Factors Impacting Adoption of Genetically Modified Cotton. AgBioForum, 12(2), 218-225.

Bryars, D. (1983). Advanced Level Statistics. Slough : University Tutorial Press.

De Graaff, J. (1985). Introduction to the economics of maize. (Unpublished manuscript).

Ecker, O., \& Qaim, M. (2008). Income and price elasticities of food demand and nutrient consumption in Malawi. Orlando: American Agricultural Economics Association.

FAO. (2010) Food security information for decision making, s.1.: FAO.

FAO. (2015). Food balance sheets 2015, s.1.: FAO.

Foster, J., Greer, J., \& Thorbecke, E. (1984). A class of decomposable poverty measures. Econometrica, 52(3), 761-766. https://doi.org/10.2307/1913475

Government of Malawi. (1983). Laws of Malawi, The Prison Act (Cap. 9:02). Zomba: Malawi Government.

Government of Malawi. (1999). Food security and nutrition bulletin, Lilongwe: Ministry of Economic Planning and Development.

Government of Malawi. (2005). Food and nutrition security policy. Lilongwe.: Ministry of Agriculture and Food Security.

Government of Malawi. (2006). Food security policy. Lilongwe: Ministry of Agriculture and Food Security.

Government of Malawi. (2006). Agricultural and livestock development strategy and action plan. Lilongwe: Ministry of Agriculture and Food Security.

Government of Malawi. (2006). Malawi growth and development strategy-from poverty to prosperity 2006-2011. Lilongwe.

Government of Malawi. (2010). Malawi millennium development goals report. Lilongwe.

Government of Malawi. (2016). Prisoner population. Malawi Prison Service Headquarters. Zomba

Greene, W. (2003). Econometric analysis, 5th edition. New Jersey: Prentice Hall.

Gujarati, D. N. (2004). Basic Econometrics. Fourth edition. McGraw-Hill.

Hoetker, G. (2007). The Use of Logit and Probit Models in Strategic Management Research: Critical issues. Strategic Management Journal, 28(4), 331-343. https://doi.org/10.1002/smj.582

IFPRI. (2012). Malawi strategy support program: Policy note 11, Lilongwe: IFPRI.

Kidane, W., Maetz, M., \& Dardel, P. (2006). Food security and agricultural development in Sub-Saharan Africa; Building a case for more public support. Rome: FAO.

Kothari, C. (2004). Research methodology: Methods and techniques, 2nd edition. New Delhi: New Age International.

Maddala, G. (1992). Introduction to Econometrics, 2nd edition . New York: MacMillan Publishing Co.

Magnani, R. (1997). Sampling guide. Impact monitoring project. Va: Arlington.

Maxwel, S., \& Frankenberger, T. (1992). Household food security: Concepts, indicators and measurements; a tecchnical review. New York: UNICEF and IFAD. 
McGill, F., McLennan, S., \& Migliorini, J. (2000). Complete Advanced Level Mathematics - Statistics . Cheltenham : Stanley Thornes.

Medecins Sans Frontieres. (2009) No food or medicine here until you die. http://www.doctorswithoutborders.org/publications/article.cfm?id=3433\&cat=special-report.

Penal Reform International. (2002). A model for good prison farm management in Africa. Penal Reform in Africa. http://www.panelreform.org/resources/rep-2002-prison-farmmanagement-eng.pdf

Sen, A. (1976). Poverty: An ordinal approach to measurement. Econometrica, 44(2), 219-231. https://doi.org/10.2307/1912718

Swindale, A., \& Bilinsky, P. (2006). Development of a universally applicable household food insecurity measurement tool: Process, current status and outstanding issues. Journal of Nutrition (136)1449s-1452s. https://doi.org/10.1093/jn/136.5.1449S

United Nations. (2015). Millenium development doals indicators. http://mdgs.un.org/unsd/mdg/metadata.aspx? IndicatorId=2.

UNDP (2011). Human development report, s.l.: UNDP.

Uzunoz, M., \& Akcay, Y. (2012). A Case Study of Probit Model Analysis of Factors Affecting Consumption of Packed and Unpacked Milk in Turkey. Economics Research International, http://dx.doi.org/10.1155/2012/732583.

Verbeck, M. (2004). A guide to modern econometrics, 2nd edition. West Sussex: John Willy \& Sons Ltd. Wooldridge J. (2002). Econometric analysis of cross sectional and panel data. Cambridge. The MIT Press.

World Bank. (2008). World development report. Washington D.C: World Bank.

Zikmund, W. G. (1997). Business research methods, fifth edition. Fort Worth: The Dryden Press.

\section{Copyrights}

Copyright for this article is retained by the author(s), with first publication rights granted to the journal.

This is an open-access article distributed under the terms and conditions of the Creative Commons Attribution license (http://creativecommons.org/licenses/by/3.0/). 